\title{
Bisphenol A Toxicity: Familiarity, Knowledge, Attitude, and Practice Among University Students in Lebanon
}

\section{Lama Assi}

American University of Beirut Medical Center

Muhieddine Labban

American University of Beirut Medical Center

\section{Fouad El-Dana}

American University of Beirut Medical Center

Divina Justina Hasbani

American University of Beirut Medical Center

Lea Moujaes

American University of Beirut Medical Center

Mounir Al-Gibbawi

American University of Beirut Medical Center

Maha Makki

American University of Beirut Medical Center

Hani Tamim ( $\nabla$ htamim@aub.edu.lb)

American University of Beirut Medical Center

\section{Research article}

Keywords: Bisphenol A, Plastic, Familiarity, Knowledge, Attitude, Practice

Posted Date: August 14th, 2019

DOI: https://doi.org/10.21203/rs.2.12717/v1

License: (c) (i) This work is licensed under a Creative Commons Attribution 4.0 International License. Read Full License 


\section{Abstract}

Background: In the absence of strict regulations, the extent of exposure to Bisphenol A (BPA) toxicity depends mainly on the consumers' own knowledge, attitude, and practices about the matter. The aim of this study was to assess the current level of familiarity and knowledge about BPA, attitude towards it, practices related to the use of BPA-containing products, and the predictors of each. Methods : We carried out a cross-sectional study among students at the American University of Beirut, Lebanon, between January and April 2017. Full-time students above the age of 18 and registered in a specific major were eligible to participate in the study. An English questionnaire that assesses familiarity, as well as knowledge, attitude, and practice (KAP) was developed based on current literature and expert opinion. Demographics, lifestyle, and level of familiarity with the topic were assessed among all participants. Predictors of familiarity, defined as knowing at least a little about BPA, were assessed among all participants using bivariate and multivariate analyses. Among students familiar with BPA, predictors of higher KAP scores were assessed by similar analyses. Adjusted odds ratios (OR) with 95\% confidence interval (Cl) were reported. Results : The level of familiarity with BPA was $23.7 \%$. Studying in a health-related field was a predictor of familiarity (adjusted OR=3.11; $\mathrm{Cl}$ : 2.08-4.66). Among those familiar with BPA, a higher study level predicted better knowledge (adjusted OR=3.03; $\mathrm{Cl}$ : 1.33-6.89) and better practices to avoid BPA (adjusted $\mathrm{OR}=2.53 ; \mathrm{Cl}: 1.08-5.97)$. Additionally, a higher family income was a predictor of higher knowledge and better practice, with an adjusted OR of 2.82 (Cl: 1.12-7.08), and 2.9 (Cl: 0.99 8.56), respectively. Father education was also a predictor of safer practices with an adjusted OR of 2.58 (Cl: 1.01-6.56). Furthermore, female gender was the only predictor of higher attitudes towards BPA and its potential health effect (adjusted OR=2.19; $\mathrm{Cl}$ : 1.08-4.46). Conclusion : Familiarity with BPA among university students in Lebanon is low. Future research is needed to determine the level of familiarity, knowledge, attitude, and practice among the general Lebanese population. Awareness campaigns and policy change are needed to ensure lower exposure to BPA.

\section{Background}

Despite the recurrent evidence about its toxicity, bisphenol A (BPA) remains widely used in daily products, with more than 2 million tons produced yearly (1). BPA is commonly found in products composed of epoxy resin and polycarbonate plastic, including reusable water bottles, food cans, pizza boxes, and dental sealants (2). It makes its way into body fluids by leaching from food and beverage containers (3). Certain stressors like ultraviolet light, microwave radiation, and moist heat can accelerate the leaching process (4). Furthermore, detectable urine levels of BPA have been identified in nearly all human urine samples studied, suggesting that the quantities of BPA currently used in industrial products are large enough to result in high concentrations in body fluids (5).

Exposure to BPA by leaching from commonly-used products results in BPA concentrations in the body that are high enough to cause adverse effects in laboratory animals, mainly rats. As an estrogen agonist, BPA can interfere with estrogen nuclear receptors making it an endocrine disruptor (6). Clinically, this has been linked to a number of adverse effects, including obesity, type 2 diabetes mellitus, cardiovascular disease, and infertility (5). Moreover, in any given community with BPA exposure, the risk for various diseases increases (7).

Despite all the evidence, the most recent risk assessments conducted by the European Food Safety Authority, the US Food and Drug Administration, and Health Canada, all conclude that BPA is safe under current exposure levels (8-10). Therefore, in the absence of strict regulations, the extent of exposure to BPA toxicity depends mainly on the consumers' own knowledge, attitude, and practices about the matter.

To date, there have been only a few studies assessing the level of familiarity, knowledge, attitude, and practices concerning BPA. A study conducted in the US showed that $70 \%$ of the people surveyed had at least heard about BPA, 
which were considered to be familiar with the topic (11). In Thailand, a study showed that while parents and health professionals know about some of the adverse effects of BPA, they do not know how to use or purchase plastic products properly, showing a lack of knowledge despite some familiarity with the topic (12). In Malaysia, a study was conducted among university students about plastic products and endocrine disrupting chemicals, including BPA, and found that $84 \%$ of the students had low knowledge while $90 \%$ had a fair attitude about the subject (13). The importance of awareness about BPA was shown in an educational intervention held in India, where following educational sessions about BPA, the mean knowledge score about BPA increased, and, more importantly, it was associated with changes in practice that were still significant three months after the intervention (3).

In Greater Beirut, it was found that total BPA levels in urine are similar to the levels found in the rest of the world, suggesting a congruent exposure to BPA toxicity (14). In fact, drinking water purchased in polycarbonate containers was found to have detectable BPA levels in the products of 13 out of 22 companies sampled in Lebanon (15). To our knowledge, no awareness campaigns about BPA and its toxicity have been held in Lebanon, although it is a topic of discussion in some university classes, on social media, and among athletes (with the increasing availability of BPAfree sports water bottles). Therefore, we conducted a study on a sample of university students in Beirut with the aim of assessing (1) the current level of familiarity with BPA, defined as the recognition of the product and its presence in plastic products, (2) knowledge about BPA, defined as a more in-depth understanding of the topic, (2) their attitude towards it, (3) practices related to the use of BPA-containing products, (4) and the predictors of each one of these variables.

\section{Methodology Study Design}

A cross-sectional study was conducted between January and April 2017 among students at the American University of Beirut (AUB), a private university in the capital of Lebanon. Ethical approval was obtained from the Institutional Review Board at AUB.

\section{Eligibility and Sampling}

Full-time students above the age of 18 and registered in a specific major were eligible to participate in the study. Freshmen and part-time students were excluded from the study. Out of the eligible students, a convenience sample of 569 participants was recruited based on the students' field and year of study. A list of all the possible combinations of student majors and study levels was developed. The minimum number of students to be included in each category was proportional to the total number of AUB students in the given category. A list of the major-required courses for each category of students was developed, and classes were randomly selected for each one. After receiving approval from the administration, self-administered questionnaires were distributed in the selected classes. As many classes as needed were visited for each category until all the minimum numbers of students needed in each category were reached.

\section{Research Instrument Construction}

To our knowledge, there is no comprehensive English questionnaire that measures familiarity, knowledge, attitude, and practice about BPA and its potential health effects. Therefore, an English questionnaire was designed based on the current literature about BPA, which is summarized in the introduction, and already-existing surveys addressing similar 
topics $(3,11,12)$. Content experts from the Faculty of Health Sciences at AUB were available throughout the process for advice and assistance in question development, and to ensure that the final questionnaire covers all the important aspects of the subject. Additionally, the questionnaire was reviewed by the Writing Center at AUB for proper question formulation, usage of familiar words, and screening for double-barrel or biased questions, thus improving its reliability. Face validity was tested by piloting the questionnaire on a sample of 20 students from different majors and classes. Their feedback was collected in one-on-one sessions where they were asked about their general impression while filling the questionnaire and about items that caused confusion, including the presence of non-mutually exclusive or misleading answers. The final version of the questionnaire was then adopted based on all the recommendations and feedback received [See Additional file 1].

\section{Variables and Data Measurement}

The questionnaire was divided into six sections: demographics, lifestyle, familiarity, knowledge, attitude, and practices related to BPA. Familiarity was determined by asking the respondents to assess their acquaintance with BPA by choosing among the options "I know a lot", "I know a little", and "I do not know" about BPA. Students who reported knowing a lot or a little about BPA were considered to be "familiar with BPA", whereas students who reported not knowing about BPA were considered "not familiar".

Scores for knowledge, attitude, and practice related to BPA were computed for those who were found to be familiar with the topic. The KAP sections of the questionnaire were disregarded for the respondents who were "not familiar with BPA" as their answers would have been based on non-informed guesses only. Therefore, the KAP analysis was done only among the students who knew at least "a little" about BPA.

Knowledge about BPA was estimated through five multiple choice questions related to (1) items containing BPA, (2) its toxic effects, (3) the leaching process, (4) practices that increase leaching, and (5) the resin identification codes. A score over 16 was computed based on the number of correct answers selected in the five questions. It was converted to a score over 100, with higher scores indicating better knowledge about BPA. Therefore, while the familiarity question measures the individuals' perceived understanding, this section is an objective evaluation of the students' factual knowledge about BPA.

Attitude about BPA toxicity was assessed through questions about the respondents' attitude toward: (1) BPA and its potential toxic effects, (2) the idea that risk of toxicity from BPA can be avoided, (3) that there should be more awareness about BPA, and (4) that there should be stricter policies about BPA. The questions used a Likert scale from 1 to 5 , with 1 representing "to a very little extent" and 5 "to a very great extent". A score from 8 to 40 was computed by adding the scale numbers together; and subsequently converted to a score over 100, with higher attitude scores meaning greater concern about BPA and its toxicity.

Practice was assessed through questions about the frequency of exposure to the following BPA-containing products: (1) canned food, (2) canned sodas and beer, (3) recycled pizza boxes, (4) microwaved/heated food and beverages in plastic containers, (5) microwaved/heated food and beverages wrapped in plastic cling film, (6) water coolers, and (7) reusable plastic bottles. Respondents answered the questions using a scale from 1 to 5 , with 1 being "every day" and 5 "never". A score from 7 to 35 was computed, then converted to a score over 100, with higher scores indicating practices that result in less BPA exposure.

The scores for the three KAP sections were then categorized into two groups based on the split median method: those above the median (higher level of knowledge/ higher attitudes/ or higher practices) versus entries scoring lower than

Page $4 / 13$ 
the median (lower knowledge/ lower attitudes/ or lower practices).

\section{Data Analysis}

Data were analyzed using the Statistical Package for Social Sciences (SPSS, version 24). Two sets of analyses were carried out: one for familiarity among all respondents $(n=569)$, and another one for the knowledge, attitude and practice scores only among those who were "familiar with BPA" $(n=135)$. Continuous data were reported as means and standard deviation (SD) and were compared between different dependent variables (familiarity with BPA, overall knowledge, overall attitudes and overall practices) using the independent Student's t-test. On the other hand, categorical data were reported as numbers and percentages and were compared using the Chi-Square test. Multivariate regression analysis was used to adjust for potentially confounding variables. The stepwise logistic regression analysis assessed the association between familiarity, knowledge, attitude, and practice and the different predictors (gender; study level; field of study; health professional as source of health information and BMI). P-value of 0.05 was set for the entry of potential predictors into the model, whereas a P-value of 0.1 was set for removal from the model. The results were presented by the odds ratio (OR) and $95 \%$ confidence interval $(\mathrm{Cl})$. P-value of $<0.05$ was considered statistically significant.

\section{Results}

A total of 569 students were included in this study. The overall characteristics of the study participants are presented in table 1 . Among the study participants $54.1 \%$ students were females and $79.4 \%$ were less than 22 years old. Students were distributed across all levels of study (year 1, 2, 3, and year 4 or graduate level) and they were enrolled in 50 different majors, with $35.9 \%$ of them enrolled in health-related fields. Moreover, $17.0 \%$ of the students reported to be smokers, and $23.4 \%$ were either overweight or obese (BMI $>25 \mathrm{~kg} / \mathrm{m}^{2}$ ). Most of the students relied on the Internet and mobile applications as a source of health information (84.2\%).

Out of the original sample $(n=569), 135$ students reported being familiar with BPA. Comparison between familiarity with BPA in terms of baseline and demographic characteristics are presented in table 2. It was found that the students who were familiar with BPA were significantly more likely to be graduate students $(33.3 \%)$ compared to those not familiar $(23.5 \%)$ ( $p$-value $=0.02)$. In addition, $57.8 \%$ of students who were familiar with BPA were enrolled in healthrelated fields ( $p$-value<0.0001). Likewise, relying on health professionals for health information was found to be significantly associated with familiarity $(72.6 \%$ vs. $55.3 \%$, p-value $<0.0001)$. Similarly, students who were familiar with BPA were more likely to use print media/TV/Radio as a source of health information, $41.5 \%$ as compared to $31.3 \%$ ( $p$ value $=0.03)$. Female gender and level of study were also significantly associated with familiarity $(p-v a l u e=0.05$, and $\mathrm{p}$-value $=0.02$, respectively).

Results of the multivariate analysis for predictors of BPA familiarity are presented in table 3. After adjusting for the confounding factors, familiarity was still significantly associated with health-related field of study and relying on health professionals for health information $(\mathrm{OR}=3.11,95 \% \mathrm{Cl}: 2.08-4.66$, and $\mathrm{OR}=1.86,95 \% \mathrm{Cl}: 1.21-2.88$, respectively).

The results of the bivariate analysis of the scores for knowledge, attitude, and practice about BPA for those who were familiar with BPA $(n=135)$ are presented in table 4 . Higher scores of knowledge were significantly associated with a higher study level $(41.8 \%$ vs. $21.2 \%$,p-value $=0.03)$, and similarly with the use of the Internet/Applications as a source of health information $(91.1 \%$ vs. $69.2 \%$, p-value $=0.001)$. A lower mother educational level was also significantly associated with higher knowledge scores ( $p$-value $=0.02$ ). However, unlike with familiarity, studying in a health-related 
field was not significantly associated with higher knowledge scores ( $p$-value $=0.32$ ). Regarding the attitude, only female gender was significantly correlated with higher scores, $70.6 \%$ as compared to $52.2 \%$ ( $p$-value $=0.03$ ). Finally, higher study level, father educational level, and monthly household income were significantly associated with higher practice scores ( $p$-value $=0.05, p$-value $=0.01$ and $p$-value $=0.03$, respectively) .

The results of the stepwise multivariate logistic regression analyses assessing the factors associated with knowledge, attitude, and practice about BPA among those familiar with the topic $(n=135)$ are presented in table 5 . It was found that being enrolled in year 4 or graduate level and coming from middle socioeconomic status were significantly correlated with higher knowledge $(\mathrm{OR}=3.03,95 \% \mathrm{Cl}: 1.33-6.89$, and $\mathrm{OR}=2.82,95 \% \mathrm{Cl}: 1.12-7.08$, respectively). As for the attitude scores, female gender was found to be the only significant predictor of a higher score $(O R=2.19,95 \%$ $\mathrm{Cl}$ : 1.08-4.46). Likewise, higher study level, father degree and household incomes were all found to be predictors of better practice $(\mathrm{OR}=2.53,95 \% \mathrm{Cl}: 1.08-5.97, \mathrm{OR}=2.58,95 \% \mathrm{Cl}: 1.01-6.56$, and $\mathrm{OR}=2.90,95 \% \mathrm{Cl}: 0.99-8.56$, respectively).

\section{Discussion}

In this cross-sectional study conducted at the American University of Beirut, Lebanon, we estimated the level of knowledge, attitude, and practice about BPA among university students and the predictors of each. The level of familiarity of BPA in our study was $23.7 \%$, a similar finding to the study done in Malaysia which found that only $32.7 \%$ were familiar with BPA as an endocrine disrupting chemical (13). Studying in health-related field was found to be a predictor of familiarity, while higher study level and higher family income were predictors of higher knowledge and better practices. Female gender was the only predictor of greater attitude.

Predictors of BPA familiarity were studying in a health-related field and relying on health professionals as a source of health information. This is similar to Malaysian university students, where although familiarity with endocrinedisrupting chemical is quite low, students in scientific domains had relatively better knowledge about the topic (13).Given the low level of familiarity with BPA and its association with exposure to the health field, it seems like most of the knowledge comes from formal or educational settings, whether directly through university classes or interaction with health professionals.

Higher study level was a predictor of both better knowledge and safer practices. As a matter of fact, higher education has been linked with greater knowledge about science and technology in general (16), and BPA in specific (11). Moreover, highly educated people were shown to be more attentive to scientific controversies and topics discussed in the news, although this was not always associated with greater factual knowledge (17). In our study, higher study level did result in greater factual knowledge and even better practices to reduce exposure to BPA. Because our study was conducted strictly among people educated at a university level, our sample did not include people without university education; therefore, the association between knowledge and having a university degree could not be assessed. Nevertheless, since students in higher years of study had better knowledge, it seems that most people are learning about BPA throughout their years of study. Knowing that no awareness campaigns have been held for the general population, one can speculate that in Lebanon, highly educated people might also show greater knowledge about BPA.

Female gender was a predictor of higher attitude scores, suggesting that women are more concerned about the health effects of BPA. This is consistent with another study about BPA, where females were also found to show greater concern about it (11). Several studies suggest that women are more engaged in seeking health information and discussing health related issues (18-20). In our study, women did not have greater knowledge or better practice, but they did show greater concern about BPA. This shows that, at least in Lebanon, concern about BPA alone is not 
enough; even if women are more worried about the negative effects of BPA, there is a lack of information on how to avoid exposure to it.

The two indicators of socioeconomic status, family income and father education, were predictors of better practice. Family income was also a predictor of better knowledge. A cross-sectional study conducted in the US showed that lower income was the most important predictor of exposure to BPA based on urine levels (21). In a study conducted in Greater Beirut, there was no significant correlation between BPA levels and income (14). However, all their participants had much lower incomes than our study participants, suggesting that our populations are different. Knowing that BPAfree alternatives are expensive and knowledge about how to avoid these products is not widely available, it is more likely that socioeconomic background does play a role in exposure to BPA, as shown in our study.

Since higher study level and higher monthly income were predictors of both better knowledge and practices, this might suggest that knowledge and practice are intertwined. Therefore, an increase in knowledge could potentially have an impact on practice. In fact, in a study that assessed the impact of education intervention on the knowledge regarding hazards of plastic food containers in school children, it was shown that interactive educational intervention resulted in higher knowledge, which translated into behavioral changes in schoolchildren for up to 3 months after the intervention (3). Similarly, the study conducted in Malaysia revealed that students are aware of the adverse effects of toxic chemical in plastic, but require more knowledge about the proper usage of these items (13). This could be used as evidence that practices could be improved with better knowledge about the matter, and encourage educational activities to raise awareness about BPA in the general population.

This study should be viewed in light of the following limitations. Due to its cross-sectional design, causality between the variables explored and the outcomes cannot be inferred. Nonetheless, predictors for each variable could be determined. Moreover, the questionnaire used was not tested for its concurrent criterion validity due to lack of any validated questionnaire in the literature. However, face validity was obtained by a pilot study on a sample of 20 students from different fields of study, and content validity was obtained from experts in the field. Finally, our study was confined to students at the American University of Beirut. Although the results might not be generalizable to the Lebanese population, our population is diverse with people from a variety of socioeconomic backgrounds and fields of study. With all its limitations, this study is the first to assess the level of knowledge, attitude, and practice about BPA in the region. Furthermore, it provides a platform for testing the efficacy of any future public health interventions, as our results can be used as a baseline to compare the knowledge, attitude, and practice of students at AUB before and after implementing interventions and awareness campaigns about BPA.

Although BPA-containing products are widely available, our study shows that knowledge about their toxicity is low, even among highly educated young people $(12,13)$. According to our study, students seem to learn about BPA throughout their years at the university, which means an even lower level of awareness is expected in the general population. Awareness campaigns must be held at the national level, starting with schools and universities, but also targeting non-educational settings. This is important since according to our findings individual behavior to reduce exposure to BPA seems to be the only way to avoid BPA toxicity (3). However, given how common BPA-containing products are, awareness alone is not enough; public health professionals should push for stricter policies concerning the use of BPA (13). Initiatives like campaigns and policy drafts can start from within the academic setting. Moreover, as we wait for stricter regulations, student-led change can be made at the local level by limiting the availability of BPAcontaining products in coffee shops and restaurants in and around the university.

\section{Conclusion}


This study demonstrated that familiarity with BPA among university students in Lebanon is low, with students in health-related fields the most familiar. Students in higher years of study and students coming from higher socioeconomic background had not only better knowledge about BPA, but also safer practices. Future research is needed to determine the level of knowledge, attitude, and practice among the general Lebanese population, and awareness campaigns and policy change are needed to ensure lower exposure to BPA.

\section{Declarations}

\section{Ethics Approval and Consent to Participate}

Ethical approval was obtained from the Institutional Review Board at the American University of Beirut. Written consents were taken from the students before filling the questionnaire.

\section{Consent for Publication}

Not applicable.

\section{Availability of Data and Material}

The datasets used and/or analyzed during the current study are available from the corresponding author on reasonable request.

\section{Competing Interests}

The authors declare that they have no competing interests.

\section{Funding}

Not applicable.

\section{Contributions}

LA and ML devised the project, the main conceptual ideas, and the questionnaire. LA, ML, FE, MA, and DH participated in the literature review, study design, and data collection. HT and MM provided statistical advice and analyzed the data. All authors participated in the interpretation of the results. LA and ML wrote the manuscript with input from all authors. All authors read and approved the final manuscript.

\section{Acknowledgments}

Not applicable.

\section{References}


1.Corrales J, Kristofco LA, Steele WB, Yates BS, Breed CS, Williams ES, et al. Global Assessment of Bisphenol A in the Environment: Review and Analysis of Its Occurrence and Bioaccumulation. Dose-response. 2015;13(3):1-29.

2.Konieczna A, Rutkowska A, Rachon D. Health risk of exposure to Bisphenol A (BPA). Roczniki Państwowego Zakładu Higieny. 2015;66(1).

3.Priya A, Toppo M, Singh D, Singh N, Sethia S. A study to assess the impact of education intervention on the knowledge regarding hazards of plastic food containers in school children. Int J Community Med Public Health. 2016;3(8):2275-80.

4.Yang CZ, Yaniger SI, Jordan VC, Klein DJ, Bittner GD. Most plastic products release estrogenic chemicals: a potential health problem that can be solved. Environmental Health Perspectives. 2011;119(7):989.

5.Rochester JR. Bisphenol A and human health: a review of the literature. Reproductive toxicology. 2013;42:132-55.

6.Routledge EJ, White R, Parker MG, Sumpter JP. Differential effects of xenoestrogens on coactivator recruitment by estrogen receptor (ER) alpha and ERbeta. The Journal of biological chemistry. 2000;275(46):35986.

7.Lang IA, Galloway TS, Scarlett A, Henley WE, Depledge M, Wallace RB, et al. Association of urinary bisphenol A concentration with medical disorders and laboratory abnormalities in adults. JAMA. 2008;300(11):1303-10.

8.Government of Canada HCHP, Food Branch FD. Bisphenol A - Packaging Materials - Food Safety - Health Canada. 2004.

9.No consumer health risk from bisphenol A exposure | European Food Safety Authority. 2016.

10.Food U, Administration D. Questions \& Answers on Bisphenol A (BPA) Use in Food Contact Applications. 2014.

11.Brewer PR, Ley BL. Multiple exposures: Scientific controversy, the media, and public responses to Bisphenol A. Science Communication. 2011;33(1):76-97.

12.Kasemsup R, Neesanan N. Knowledge, attitudes and practices relating to plastic containers for food and drinks. J Med Assoc Thai. 2011;94 Suppl 3:S121-5.

13.Ck H, Kamarudin K, Hm Y. University Students' Knowledge, Attitude, and Practice (KAP) of Endocrine Disrupting Chemicals (EDCs)L The Use of Selected Plastic-Type Food Contact Materials in Kuala Terengganu. IOSR Journal of Nursing and Health Science. 2017;06(01):10-6.

14.Mouneimne Y, Nasrallah M, Khoueiry-Zgheib N, Nasreddine L, Nakhoul N, Ismail H, et al. Bisphenol A urinary level, its correlates, and association with cardiometabolic risks in Lebanese urban adults. Environmental Monitoring and Assessment. 2017;189(10):1-13.

15.Dhaini HR, Nassif RM. Exposure assessment of endocrine disruptors in bottled drinking water of Lebanon. Environmental Monitoring and Assessment. 2014;186(9):5655-62.

16.Nisbet MC, Scheufele DA, Shanahan J, Moy P, Brossard D, Lewenstein BV. Knowledge, Reservations, or Promise? Communication Research. 2002;29(5):584-608.

17.Brossard D, Nisbet MC. Deference to Scientific Authority Among a Low Information Public: Understanding U.S. Opinion on Agricultural Biotechnology. International Journal of Public Opinion Research. 2007;19(1):24-52. 
18.Ek S. Gender differences in health information behaviour: a Finnish population-based survey. Health Promotion International. 2015;30(3):736-45.

19.Lorence D, Park H. Gender and online health information: a partitioned technology assessment. Health Information \& Libraries Journal. 2007;24(3):204-9.

20.Renahy E, Parizot I, Chauvin P. Determinants of the frequency of online health information seeking: Results of a Web-based survey conducted in France in 2007. Informatics for Health and Social Care. 2010;35(1):25-39.

21.Nelson JW, Scammell MK, Hatch EE, Webster TF. Social disparities in exposures to bisphenol A and polyfluoroalkyl chemicals: a cross-sectional study within NHANES 2003-2006. Environmental Health. 2012;11(10).

\section{Tables}

Table 1: Demographics of survey respondents

\begin{tabular}{|c|c|c|}
\hline Variables & Frequencies & Percentage (\%) \\
\hline \multicolumn{3}{|l|}{ Gender } \\
\hline Female & 308 & 54.1 \\
\hline Male & 261 & 45.9 \\
\hline \multicolumn{3}{|l|}{ Age } \\
\hline$<22$ & 452 & 79.4 \\
\hline$\geq 22$ & 117 & 20.6 \\
\hline \multicolumn{3}{|l|}{ Study level } \\
\hline UG Year 1 & 141 & 24.8 \\
\hline UG Year 2 & 140 & 24.6 \\
\hline UG Year 3 & 141 & 24.8 \\
\hline UG Year 4/Graduate & 147 & 25.8 \\
\hline \multicolumn{3}{|l|}{ Field of study } \\
\hline Health-related & 204 & 35.9 \\
\hline Non health-related & 365 & 64.1 \\
\hline \multicolumn{3}{|l|}{ Mother's highest degree } \\
\hline High school or less & 171 & 30.2 \\
\hline University level & 396 & 69.8 \\
\hline \multicolumn{3}{|l|}{ Father's highest degree } \\
\hline High school or less & 124 & 21.9 \\
\hline University level & 441 & 78.1 \\
\hline \multicolumn{3}{|l|}{ Monthly household income } \\
\hline$<\$ 2,999$ & 109 & 34.4 \\
\hline$\$ 3,000-\$ 5,999$ & 123 & 38.8 \\
\hline$>\$ 6,000$ & 85 & $\frac{2.0}{26.8}$ \\
\hline \multicolumn{3}{|l|}{ Lived abroad } \\
\hline Yes & 242 & 42.7 \\
\hline No & 327 & 57.3 \\
\hline \multicolumn{3}{|l|}{ Cigarette smoking } \\
\hline Yes & 97 & 17.0 \\
\hline No & 472 & 83.0 \\
\hline \multicolumn{3}{|l|}{ Body Mass Index (BMI) } \\
\hline$<18.5$ & 25 & 4.6 \\
\hline $18.5-25$ & 395 & 72.1 \\
\hline$>25$ & 128 & 23.4 \\
\hline \multicolumn{3}{|l|}{ Source of health information } \\
\hline Internet/applications & 479 & 84.2 \\
\hline Health professionals & 338 & 59.4 \\
\hline Family/friends & 314 & 55.2 \\
\hline Print media/TV/radio & 191 & 33.6 \\
\hline
\end{tabular}

Table 2: Bivariate analysis for the variables associated with BPA familiarity 


\begin{tabular}{|c|c|c|c|}
\hline & \multicolumn{3}{|c|}{ Familiarity with BPA } \\
\hline & Yes & No & p-value \\
\hline Variables & $\%$ & $\%$ & \\
\hline \multicolumn{4}{|l|}{ Gender } \\
\hline Female & 61.5 & 51.8 & 0.05 \\
\hline Male & 38.5 & 48.2 & \\
\hline \multicolumn{4}{|l|}{ Age } \\
\hline$<22$ & 75.6 & 80.6 & 0.20 \\
\hline$\geq 22$ & 24.4 & 19.4 & \\
\hline \multicolumn{4}{|l|}{ Study level } \\
\hline UG Year 1 & 15.6 & 27.6 & 0.02 \\
\hline UG Year 2 & 25.2 & 24.4 & \\
\hline UG Year 3 & 25.9 & 24.4 & \\
\hline UG Year $4 /$ Graduate & 33.3 & 23.5 & \\
\hline \multicolumn{4}{|l|}{ Field of study } \\
\hline Health-related & 57.8 & 29.0 & $<0.0001$ \\
\hline Non health-related & 42.2 & 71.0 & \\
\hline \multicolumn{4}{|l|}{ Mother's highest degree } \\
\hline High school or less & 24.4 & 31.9 & 0.10 \\
\hline University level & 75.6 & 68.1 & \\
\hline \multicolumn{4}{|l|}{ Father's highest degree } \\
\hline High school or less & 18.7 & 23.0 & 0.29 \\
\hline University level & 81.3 & 77.0 & \\
\hline \multicolumn{4}{|l|}{ Monthly household income } \\
\hline$<\$ 3,000$ & 36.5 & 33.6 & 0.89 \\
\hline$\$ 3,000-\$ 5,999$ & 37.6 & 39.2 & \\
\hline$>\$ 6,000$ & 25.9 & 27.2 & \\
\hline \multicolumn{4}{|l|}{ Lived abroad } \\
\hline Yes & 46.3 & 41.6 & 0.34 \\
\hline No & 53.7 & 58.4 & \\
\hline \multicolumn{4}{|l|}{ Cigarette smoking } \\
\hline Yes & 14.1 & 18.0 & 0.29 \\
\hline No & 85.9 & 82.0 & \\
\hline \multicolumn{4}{|l|}{ Body Mass Index (BMI) } \\
\hline$<18.5$ & 7.5 & 3.6 & 0.17 \\
\hline $18.5-25$ & 70.7 & 72.5 & \\
\hline$>25$ & 21.8 & 23.9 & \\
\hline \multicolumn{4}{|l|}{ Source of health information } \\
\hline Internet/applications & 83.0 & 84.6 & 0.66 \\
\hline Health professionals & 72.6 & 55.3 & $<0.0001$ \\
\hline Family/friends & 51.1 & 56.5 & 0.28 \\
\hline Print media/TV/radio & 41.5 & 31.1 & 0.03 \\
\hline
\end{tabular}

Table 3: Multivariate analysis for the significant predictors of familiarity with BPA

\begin{tabular}{|l|l|l|}
\hline Variables & OR (95.0\% CI) & p-value \\
\hline Field of study & \multicolumn{2}{|l|}{} \\
\hline Non health-related & 1 & \\
\hline Health-related & $3.11(2.08,4.66)$ & $<0.0001$ \\
\hline Health professionals & 1 & \\
\hline No & $1.86(1.21,2.88)$ & 0.005 \\
\hline Yes
\end{tabular}

Variables included in the model were: Gender (reference: female); study level (reference: UG year 1); Field of study (reference: non health-related majors); Health professionals as source of health information (reference: no); BMI (reference: <18.5).

Table 4: Categorized K.A.P. scores and results of the bivariate analysis among those familiar with BPA $(\mathrm{N}=135)$ 


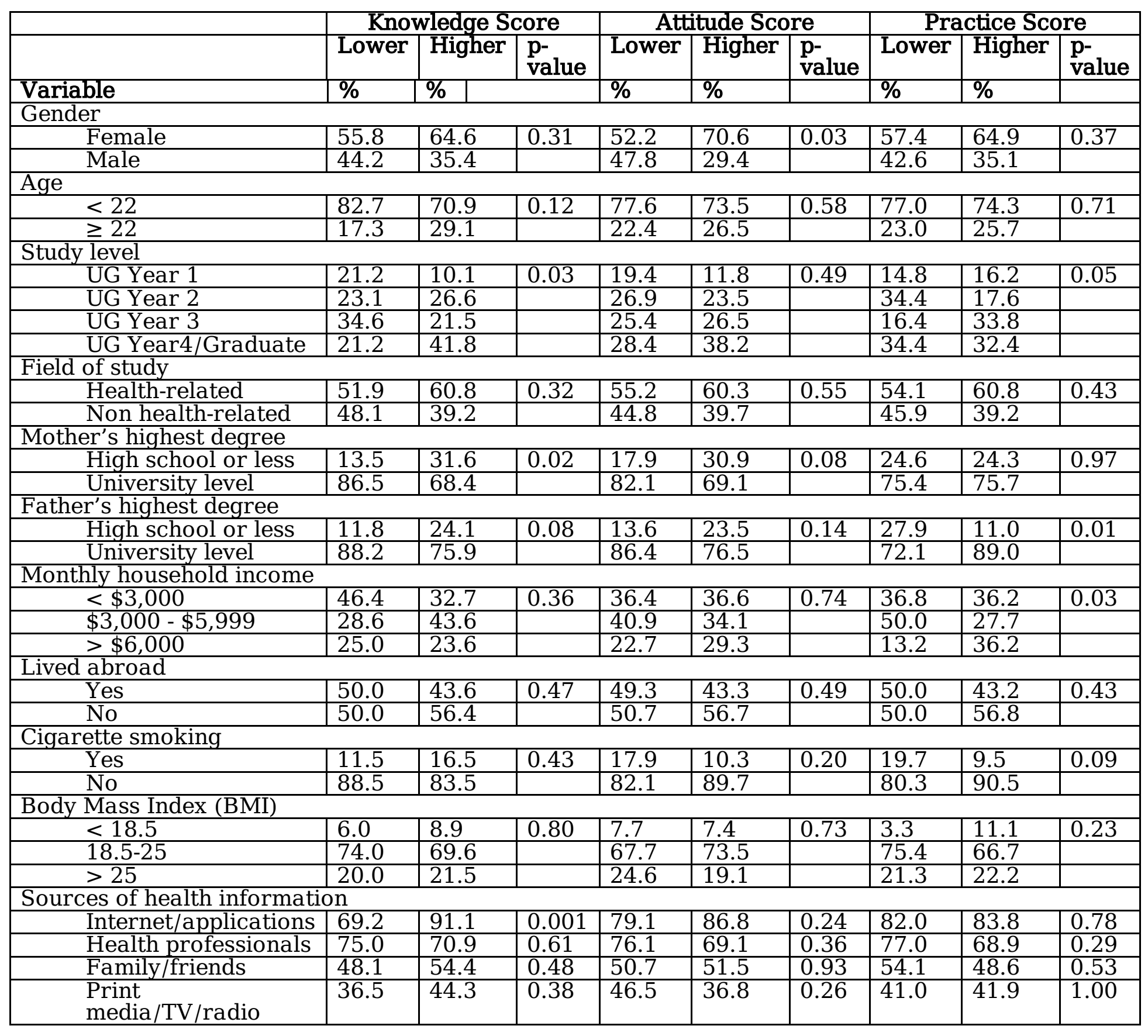

Table 5: Stepwise multivariate logistic regression of predictors of K.A.P. about BPA among those familiar with BPA $(\mathrm{N}=135)$ 


\begin{tabular}{|c|c|c|c|c|c|c|}
\hline & Knowledge S & core & Attitude Sc & & Practice Sc & pre \\
\hline Variables & OR $(95.0 \% \mathrm{CI})$ & $\begin{array}{l}\text { p- } \\
\text { value }\end{array}$ & OR (95.0\% CI) & $\begin{array}{l}\text { p- } \\
\text { value }\end{array}$ & OR (95.0\% CI) & $\begin{array}{l}\text { p- } \\
\text { value }\end{array}$ \\
\hline Gender & & & & & & \\
\hline Male & & & & & & \\
\hline Female & & & $\begin{array}{l}2.19(1.08- \\
4.46)\end{array}$ & 0.03 & & \\
\hline Study level & & & & & & \\
\hline UG Year 1 & 1 & & & & & \\
\hline UG Year 3 & & & & & $\begin{array}{l}2.53(1.08- \\
5.97)\end{array}$ & 0.05 \\
\hline $\begin{array}{l}\text { UG Year } \\
\text { 4/Graduate }\end{array}$ & $\begin{array}{l}3.03(1.33- \\
6.89)\end{array}$ & 0.01 & & & & \\
\hline Father's highest degre & & & & & & \\
\hline $\begin{array}{l}\text { High school or } \\
\text { less }\end{array}$ & & & & & 1 & \\
\hline University level & & & & & $\begin{array}{l}2.58(1.01- \\
6.56)\end{array}$ & 0.05 \\
\hline Monthly household inc & me & & & & & \\
\hline$<\$ 3,000$ & 1 & & & & 1 & \\
\hline$\$ 3,000-\$ 5,999$ & $\begin{array}{l}2.82(1.12- \\
7.08)\end{array}$ & 0.03 & & & & \\
\hline$>\$ 6,000$ & & & & & $\begin{array}{l}2.90(0.99- \\
8.56)\end{array}$ & 0.05 \\
\hline
\end{tabular}

Variables included in the model: Gender (reference: male); study level (reference: UG year 1); Field of study (reference: no health-related majors); Mother's highest degree (reference: high school or less); Father's highest degree (reference: high school or less); income (reference: <\$3,000); cigarette smoking (reference: no); Health professional (reference: no); BMI (reference: <18.5)

\section{Additional File Details}

Additional file 1-BPA Familiarity, Knowledge, Attitude, and Practice Questionnaire

This is the questionnaire used for data collection in PDF format.

\section{Supplementary Files}

This is a list of supplementary files associated with this preprint. Click to download.

- Additionalfile.pdf

- STROBEchecklistv4crosssectional.pdf 